\title{
Photocatalytic Decolourization of Chlorophyllins E141(ii) on Irradiated $\mathrm{TiO}_{2}$
}

\author{
Wojciech Zmudziński*, Karolina Doba, Tomasz Pawłowski \\ Department of Food Commodity Science, Faculty of Commodity Science, \\ Poznań University of Economics and Business, \\ Niepodległości 10, 61-875 Poznań, Poland
}

Received: 20 November 2016

Accepted: 16 January 2017

\begin{abstract}
This paper presents the results of research on the possibility of photodecolourization of trace amounts of copper complexes of chlorophyllins (E141(ii) commercial dye) in water (sewage). Experiments were carried out in model UV-VIS/E141 (ii)/TiO $/ \mathrm{H}_{2} \mathrm{O}$ and UV-VIS/E141(ii)/ $\mathrm{H}_{2} \mathrm{O}$ systems. The degree of decolourization of the dye was determined spectrophotometrically. The loss of dye in a UV-VIS/E141(ii)/TiO $/ \mathrm{H}_{2} \mathrm{O}$ system was directly proportional to the initial substance concentration and ranged from $55 \%$ to $82 \%$, depending on the initial concentration of the dye in the solution. Kinetic studies confirmed that over a range of examined concentrations of dye E141(ii), the photocatalytic decolourization process occurs in accordance with the commonly acknowledged Langmuir-Hinshelwood model. The course of changes in $\mathrm{pH}$ upon exposure indicates the formation of acidic derivatives of chlorophyllins. We found that the amount of photodegradable dye strongly depends on the initial $\mathrm{pH}$ of the solution. The increase of the $\mathrm{pH}$ of the solution inhibited the process of photocatalytic decolourization of E141(ii), whose yield reached a minimum value at $\mathrm{pH} 8$. Results of this study confirm that the photocatalytic processes can be an alternative to traditional methods of food industry sewage treatment.
\end{abstract}

Keywords: photodegradation, heterogeneous catalysis, homogeneous catalysis, dyes, advanced oxidation processes, decolourization

\section{Introduction}

The food industry produces large amounts of waste, including sewage with multiple components. Wastewater contains large amounts of matter coming from processed raw foods, such as leftover detergents, food additives (preservatives, dyes), etc. Wastewater is usually purified mechanically or chemically or with the use of combined mechanical-biological methods (aerobic and anaerobic

*e-mail: wojciech.zmudzinski@ue.poznan.pl processes) [1]. However, such purification is not complete: water requires additional cleaning treatment [2]. Developed over the course of more than 30 years, advanced oxidation process methods (AOP) seem to be an alternative to conventional methods of water purification. AOP methods are based on the oxidative potential of hydroxyl radicals $\bullet \mathrm{OH}$ generated in various ways, which can be used for degradation of organic compounds, including inorganic water pollutants [3]. The generation of these highly active radicals is possible with the use of ozonation, the action of hydrogen peroxide, Fenton and photo-Fenton reactions, plasma oxidation, and with the 
use of heterogeneous photocatalysis on semiconductors [4-9]. In the last-mentioned method irradiation of the surface of the semiconductor with light of an appropriate energy (for $\mathrm{TiO}_{2} \leq 400 \mathrm{~nm}$ ) results in the formation of electron-hole pairs $(\mathrm{e}-$ and $\mathrm{h}+$ ). If the time of existence of these chemical species is sufficiently long, they can react with water molecules and oxygen dissolved in water, leading to the formation of hydroxyl radicals. -OH radicals react immediately and non-selectively with the majority of organic compounds, leading ultimately to total mineralization, i.e., to $\mathrm{CO}_{2}$ and $\mathrm{H}_{2} \mathrm{O}$ [10-11; a diagram of the processes can be found elsewhere: 5, 11-15]. Currently, photocatalytic processes are used to remove odorous compounds [16]; ions of certain metals from water [17-18]; degrade pesticides, dioxins, furans, synthetic mono- and diazo- dyes [19-20]; and many other water contaminants [21-22].

The results of our previous studies confirm that the photocatalytic process on semiconductors can be successfully used for purifying wastewater from the dairy industry [23-24]. This work is focused on the photocatalytic degradation studies of stable and easily soluble chemicals in water-popular food coloring such as chlorophyllins (E141(ii)) on illuminated $\mathrm{TiO}_{2}$ under UV-VIS irradiation. Chlorophyllins (Fig. 1), obtained for example by the exchange of magnesium ions in chlorophyll with copper, are one of the most commonly used natural dyes in food processing. Moreover, they have also successfully been applied in medicine [25-26].

We should mention that in the case of exposing the dye to VIS radiation, the photodegradation process may also occur as a result of other possible mechanisms that involve the excitation of the dye onto the surface of the semiconductor [27]. Organic synthetic and natural dyes with visible light-absorbing chromophores have been successfully used for photosensitizing wide-gap $\mathrm{TiO}_{2}$ semiconductors. During the process, dye adsorbed physically or chemically onto the surface of $\mathrm{TiO}_{2}$ is excited by visible light. Electrons from the excited dye

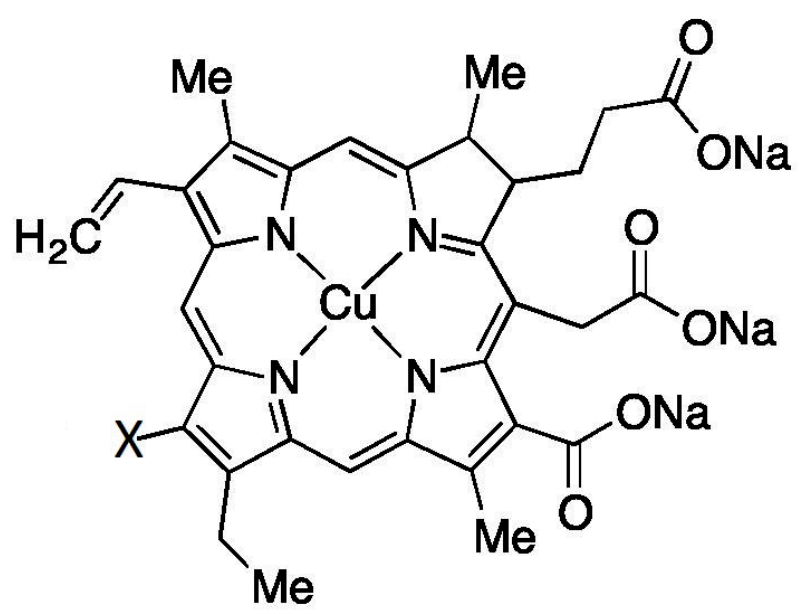

Fig. 1. Chemical structure of sodium-cooper chlorophyllins $\mathrm{a}\left(\mathrm{x}=\mathrm{CH}_{3}\right)$ and $\mathrm{b}(\mathrm{x}=\mathrm{CHO})$. are injected into the conduction band of a semiconductor and an oxidized dye radical is produced. The dye molecule becomes both sensitizer and a substrate to be degraded [28-29].

However, the primary goal of this study was to evaluate the overall impact of UV-VIS radiation emitted by solar lamps (imitating natural sunlight) on the process of photocatalytic degradation of E 141(ii) dye in the presence of titanium dioxide.

\section{Experimental}

We conducted photocatalytic studies using aqueous dye E141 (ii) containing $1.3 \%$ of the active colorant and an additive: $\mathrm{NaOH}$ (Hoffmann food aromatics). Initial concentrations of aqueous E 141(ii) solutions prepared directly before performing photoctalytic processes were: $5.20 \cdot 10^{-3}, 1.04 \cdot 10^{-2}, 1.56 \cdot 10^{-2}, 2.08 \cdot 10^{-2}$, and $2.60 \cdot 10^{-2} \mathrm{~g} \cdot \mathrm{dm}^{-3}$. All concentrations were prepared from solution with three months shelf-life after the first opening received from the producer. In all photocatalytic experiments, $230 \mathrm{~cm}^{3}$ of the solution of an appropriate concentration of dye was mixed with $0.05 \mathrm{~g}$ of $\mathrm{TiO}_{2}$ (99.9\%, Aldrich, anatase), and treated with ultrasonic waves for 10 minutes to obtain homogeneous suspension. The mixture was transported to a batch glass reactor (Pyrex, volume $250 \mathrm{~cm}^{3}$ ) designed by Sobczyński and co-workers [4]. The reactor was used previously in studies on photocatalytic degradation of organic compounds contaminating food industry waste [30]. The scheme of the photocatalytic reactor is presented in Fig. 2.

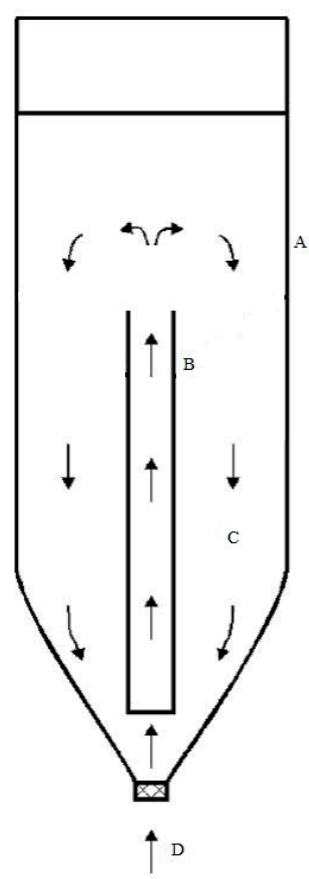

Fig. 2. Reactor used during photocatalytic and photolysis processes: A - reactor, B - inner tube, C - irradiated slurry, D - air flow. 
The slurry was flushed with an air stream $\left(50 \mathrm{~cm}^{3} \cdot \mathrm{min}^{-1}\right)$ for 15 minutes. Photocatalytic reactions were run for 35 minutes. The reactor was irradiated by two xenon $300 \mathrm{~W}$ (Osram) lamps located $50 \mathrm{~cm}$ from the reactor. The distance between the lamps was $100 \mathrm{~cm}$. The light intensity measured with Volt Craft LX-1108 light meter was 33,700 Lux. The radiation spectrum range amounted to $280-3,000 \mathrm{~nm}$. The temperature of the mixture was kept at $30 \pm 1^{\circ} \mathrm{C}$ owing to the applied air stream. To determine the kinetics of the photocatalytic process in a $\mathrm{UV} / \mathrm{H}_{2} \mathrm{O} / \mathrm{TiO}_{2}$ system, $2 \mathrm{~cm}^{3}$ of the reaction suspension was taken from the reactor for measuring absorbance with a spectrophotometer, respectively at $5,10,15,25$, and 35 minutes of exposure. The E141(ii) concentrations were read from calibration curves prepared before photodecolorization. Before measuring, the sample was filtered using a filter with a pore size of $0.22 \mu \mathrm{m}$ (PTFE, BGB Analytik AG). The absorbance measurements were made by means of a Genessys 6 spectrophotometer (Thermo Spectronic) at a wavelength of $405 \mathrm{~nm}$ (experimentally determined absorption maxima of the dye E141(ii)). The same concentrations of the dye were used in experiments carried out in a $U V / \mathrm{H}_{2} \mathrm{O}$ system (homogeneous photolysis). $\mathrm{pH}$ of the irradiated solutions was measured with a Mettler Toledo MPC 227 apparatus at intervals corresponding to sampling for spectrophotometric measurements. Furthermore, studies on the influence of initial $\mathrm{pH}$ on efficiency of photocatalytic decolourization of the E141(ii) dye were carried out using three concentrations of the colorant. Starting $\mathrm{pH}$ of the reaction mixtures was 2, 4, 6, 8, and 10. Each experiment was repeated at least twice. We used still water doubly distilled in quartz glass in all tests. Titanium dioxide had a BET-specific surface area of $11.9 \mathrm{~m}^{2} \cdot \mathrm{g}^{-1}$ as measured on a Micrometrics ASAP 2010 apparatus.

\section{Results and Discussion}

In the photocatalytic experiments we used E141(ii) dye, which includes copper complexes of chlorophyllins. In order to carry out spectrophotometric measurements, the appropriate wavelength of the light radiation (maximum absorbance) was selected: $405 \mathrm{~nm}$, based on absorption spectrum in the range of 280 to $700 \mathrm{~nm}$. All subsequent spectrophotometric measurements were carried out at this wavelength. Equations of absorbance vs. concentration of dye were determined experimentally and have the form: $\mathrm{y}=0.006 \mathrm{x}$ for unmodified $\mathrm{pH}, \mathrm{y}=0.003 \mathrm{x}$ for $\mathrm{pH}=2, \mathrm{y}=0.004 \mathrm{x}$ for $\mathrm{pH}=4$, $\mathrm{y}=0.005 \mathrm{x}$ for $\mathrm{pH}=6$, and $\mathrm{y}=0.006 \mathrm{x}$ for $\mathrm{pH} 8-11$. Coefficient of determination for all equations was 0.999. The photocatalytic decolourization of E141(ii) dye was performed at the initial substrate concentrations of $5.20 \cdot 10^{-3}, 1.04 \cdot 10^{-2}, 1.56 \cdot 10^{-2}, 2.08 \cdot 10^{-2}$, and $2.60 \cdot 10^{-2} \mathrm{~g} \cdot \mathrm{dm}^{-3}$. Changes of the substrate concentrations (according to absorbance decrease) during UV-VIS irradiation are shown in Fig. 3.

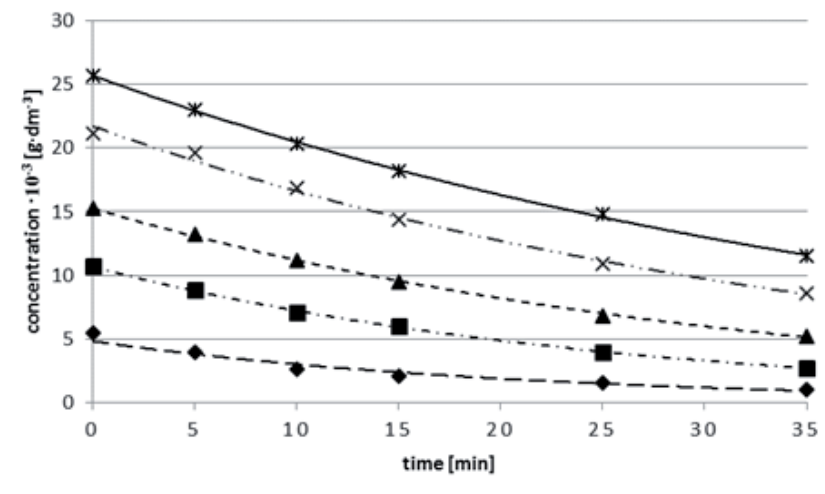

Fig. 3. Kinetic curves of E141(ii) delay vs. time, substrate concentration $0.0055,0.0107,0.0153,0.0211,0.0257\left[\mathrm{~g} \cdot \mathrm{cm}^{-3}\right]$.

It is believed that the photocatalytic degradation of organic water pollutants takes place in accordance with the model of Langmuir-Hinshelwood [30-31]. According to the model, the process in liquid-solid phase consists of the reaction between the substrate molecules adsorbed on the surface of the photocatalyst and the photogenerated hydroxyl radicals. The rate of the process depends on the rate of the reaction between radical and adsorbed molecules and is directly proportional to the concentration of the substrate adsorbed on the surface of the photocatalyst, which in turn is directly proportional to the concentration of the pseudo-first order reaction kinetics solution. The linear form of the Langmuir-Hinshelwood equation is [3233]:

$$
\frac{1}{r}=\frac{1}{k \cdot K} \cdot \frac{1}{c}+\frac{1}{k}
$$

...where $c_{o}$ is the substrate concentration in water, $k$ is the rate constant, and $K_{a d s}$ is the constant of adsorption equilibrium.

The curves presented in Fig. 2 helped to determine the initial reaction rates $(\mathrm{r} 0)$ by fitting each exponential function $\mathrm{f}(\mathrm{t})=\mathrm{Ae}^{-\mathrm{kt}}$ (calculated by Microsoft Excel). The reaction rates were calculated for $t=0$. The use of the initial reaction rate avoids the impact of intermediates formed during the photocatalytic process on the reaction rate of the main substrate E141(ii) dye. The initial reaction rates for the different initial concentrations of the substrate are presented in Table 1.

Table 1. Initial reaction rates of E141(ii) photodecolourization.

\begin{tabular}{|c|c|}
\hline $\begin{array}{c}\text { Substrate concn. } \\
\left(\mathrm{g} \cdot \mathrm{dm}^{-3}\right)\end{array}$ & $\begin{array}{c}\text { Initial reaction rate } \\
\mathrm{r}_{0}\left(\mathrm{~g} \cdot \mathrm{dm}^{-3} \cdot \mathrm{s}^{-1}\right)\end{array}$ \\
\hline $5.20 \cdot 10^{-3}$ & $5.15 \cdot 10^{-6}$ \\
\hline $1.04 \cdot 10^{-2}$ & $7.02 \cdot 10^{-6}$ \\
\hline $1.56 \cdot 10^{-2}$ & $8.03 \cdot 10^{-6}$ \\
\hline $2.08 \cdot 10^{-2}$ & $9.53 \cdot 10^{-6}$ \\
\hline $2.60 \cdot 10^{-2}$ & $9.68 \cdot 10^{-6}$ \\
\hline
\end{tabular}




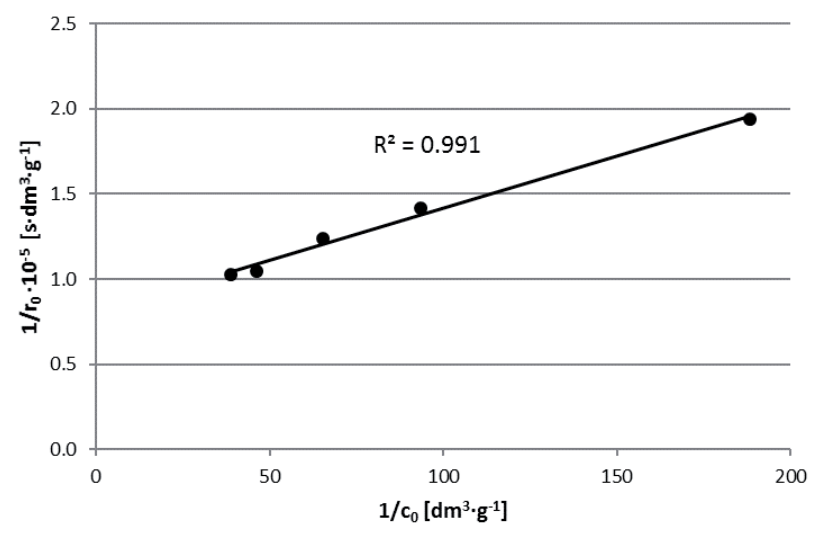

Fig. 4. Plot $1 / \mathrm{r}_{0}$ vs. $1 / \mathrm{c}_{0}$ for E141(ii).

A plot of $1 / r_{0}$ versus $1 / c_{0}$ is shown in Fig. 4. The obtained dependence is linear, which confirms the validity of the Langmuir-Hinshelwood model.

Therefore, the reaction fulfills pseudo-I-range reaction kinetics [11, 34-35]. The data contained in Table 1 were also used to calculate kinetic constants of photodecolourization process of the dye E141(ii), rate constant $\mathrm{k}$, and the adsorption equilibrium constant $\mathrm{K}_{\text {ads }}$. The determined values are: $\mathrm{k}=1.2310^{-5} \mathrm{~s}^{-1}$ and $\mathrm{K}_{\text {ads. }}=1.33 \cdot 10^{-2} \mathrm{dm}^{3} \cdot \mathrm{g}^{-1}$.

Table 2 shows the results of 35-minute exposure of an aqueous solution of the E141(ii) dye in UV-VIS/ $\mathrm{H}_{2} \mathrm{O} /$ $\mathrm{TiO}_{2}$ and UV-VIS/ $\mathrm{H}_{2} \mathrm{O}$ (photolysis process) systems. The experiments were carried out to determine the contribution of direct photolysis in photocatalytic decolourization of the investigated dye.

In the presence of $\mathrm{TiO}_{2}$, absorbance change depends on the initial concentration of the solution and ranges from $55 \%$ for the solution with the highest concentration up to nearly $82 \%$ for the solution with the lowest concentration. The amount of oxidized E141(ii) increases with an increase of solution concentration. During the 35-minute illumination of solutions without titanium dioxide, photodecolourization also took place, but with lower efficiency: from almost $17 \%$ for the lowest

Table 2. The photodecolourization of E141(ii) during 35-minute illumination of $230 \mathrm{~cm}^{3}$ of the solution with and without the presence of $\mathrm{TiO}_{2}$.

\begin{tabular}{|c|c|c|}
\hline Concentration E141(ii) & \multicolumn{2}{|c|}{$\begin{array}{c}\text { Absorbance decrease } \\
(\%)\end{array}$} \\
\hline$\left(\mathrm{g} \cdot \mathrm{dm}^{-3}\right)$ & $\mathrm{TiO}_{2}$ & $\mathrm{UV} / \mathrm{H}_{2} \mathrm{O}$ \\
\hline 1 & 2 & 3 \\
\hline $5.20 \cdot 10^{-3}$ & $81.8 \pm 0.3$ & $16.9 \pm 0.8$ \\
\hline $1.04 \cdot 10^{-2}$ & $74.8 \pm 1.3$ & $19.5 \pm 0.3$ \\
\hline $1.56 \cdot 10^{-2}$ & $66.0 \pm 0.3$ & $20.9 \pm 0.8$ \\
\hline $2.08 \cdot 10^{-2}$ & $59.2 \pm 1.4$ & $21.0 \pm 1.0$ \\
\hline $2.60 \cdot 10^{-2}$ & $55.2 \pm 0.7$ & $24.0 \pm 2.5$ \\
\hline
\end{tabular}

concentrated solution up to about $24 \%$ for the solution with the highest concentration of the substrate. In addition, during irradiation in the absence of titanium dioxide, the amount of photodecolourized dye increases with the increase of the initial concentration in the solution. This indicates that the photolysis reaction in the UV-VIS/E 141(ii) $/ \mathrm{H}_{2} \mathrm{O}$ system also proceeded in accordance with first-order reaction kinetics.

The absorption spectrum of chlorophyllins recorded in the UV-VIS region shows different absorption bands characteristic for porphyrin and porphyrin derivatives: intense absorption in the Soret band (B) appeared in the wavelength range $360-490 \mathrm{~nm}$, the band labeled Q-band in the range $500-700 \mathrm{~nm}$, and band $\mathrm{N}$ in the $240-320 \mathrm{~nm}$ region $[29,36]$. The spectra of $\mathrm{E} 141$ (ii) dye in visible parts have maximum absorbance at 405 and $626 \mathrm{~nm}$. It is seen from Figs 5(a-b) that the absorbance intensity decreases for both dye solutions (UV-VIS/E141(ii) $/ \mathrm{H}_{2} \mathrm{O} / \mathrm{TiO}_{2}$ and UV-VIS/E141(ii) $/ \mathrm{H}_{2} \mathrm{O}$ systems) with increasing times of irradiation exposure. Also, no new absorption peaks appear during the reaction, which suggests that during photocatalytic and direct photolysis processes probably a small amount of dye was photodegradated, and also that intermediate products formed during photodegradation were successfully degradated. Mainly, the decay of the groups responsible for the color of chlorophyllin occur

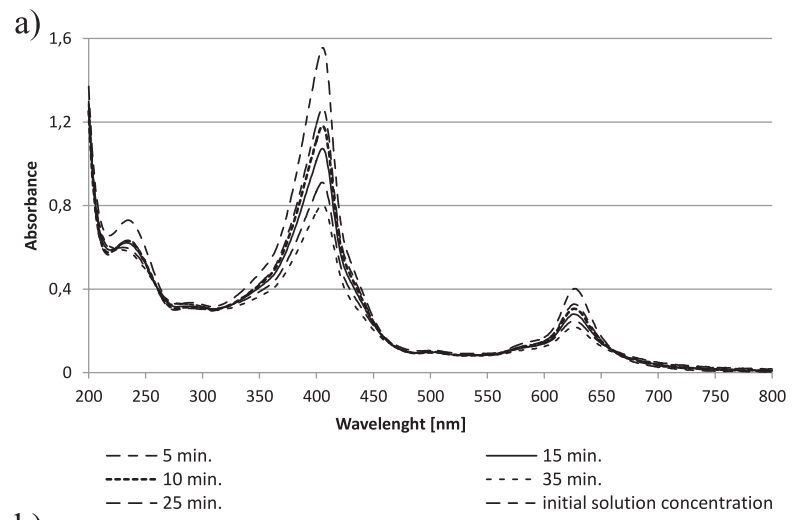

b)

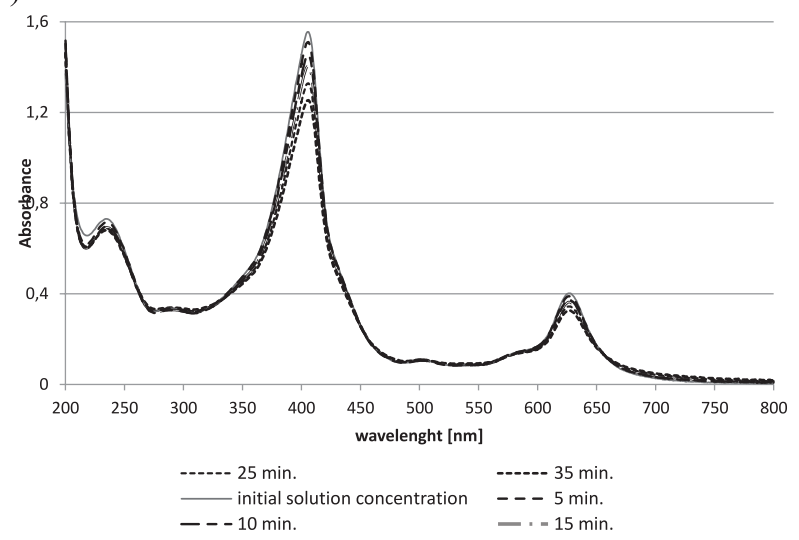

Fig. 5. Decolourization process during 35-min reaction for E141(ii); initial solution concentration $0.026 \mathrm{~g} \cdot \mathrm{dm}^{-3}$ : a) UV-VIS/E141/ $\mathrm{H}_{2} \mathrm{O} / \mathrm{TiO}_{2}$ system, b) (UV-VIS/E141/ $\mathrm{H}_{2} \mathrm{O}$ system. 
and the small amount formed during photodegradation, and intermediate products cannot be determined spectrophotometrically.

During the research on photocatalytic decolourization of E141(ii), $\mathrm{pH}$ of the irradiated solution was measured at time intervals corresponding to collecting samples for spectrophotometric measurement. The observed results of $\mathrm{pH}$ changes during illumination of the solutions in the presence of $\mathrm{TiO}_{2}$ are shown in Fig. 6 .

As seen in Fig. 6, photodegradation of copper complexes of chlorophyllins in the presence of $\mathrm{TiO}_{2}$ lead to the formation of acidic products. Similarly, acidic derivatives are produced during irradiation of the solutions of E141(ii) with no titania additives. The formation of acidic-type products is not surprising if one takes into account the fact that highly active hydroxyl radicals are the oxidative media. Moreover, the structure of chlorophyllins make it very susceptible for $\bullet \mathrm{OH}$ attacks. The problems of hydroxyl radical formation in the presence of illuminated semiconductors is that their reactions with organic molecules, the influence of substrate properties, and $\mathrm{pH}$ influence on the photoreaction rate, etc., have been subjected to many studies in the past 40 years $[5,37]$. It should be mentioned here that knowledge of the factors determining high efficiency of photocatalytic degradation of organic compounds is important for designing and operating technological processes of water and wastewater purification using photocatalysis.

The subject of this investigation, E141(ii) dye, is a porphyrin-type complex in which $\mathrm{Cu}^{2+}$ is surrounded by four nitrogen atoms. Stability of the complex depends on $\mathrm{pH}$ of the solution. Moreover, disintegration of the complex causes the release of copper(II) ions, which in turn shows a certain photoactivity. Therefore, the goal of our research also included studies on $\mathrm{pH}$ dependence of E141(ii) dye photocatalytic destruction. The photocatalytic experiments were performed using three different dye concentrations: $0.0055,0.0153$, and $0.0257 \mathrm{~g} \cdot \mathrm{dm}^{-3}$, and at five $\mathrm{pHs}$ of the starting solutions: $2,4,6,8$, and 10 . Before the photocatalytic experiments, UV-VIS absorption spectra of E141(ii) solutions were

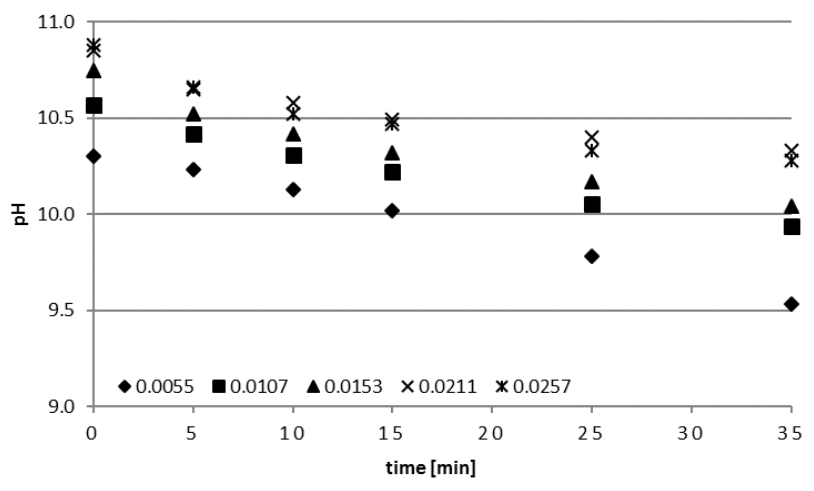

Fig. 6. Changes in $\mathrm{pH}$ during 35-minute illumination of E141(ii) solutions with the presence of $\mathrm{TiO}_{2}$ and substrate concentrations of $0.0055,0.0107,0.0153,0.0211$, and $0.0257 \mathrm{~g} \cdot \mathrm{dm}^{-3}$.

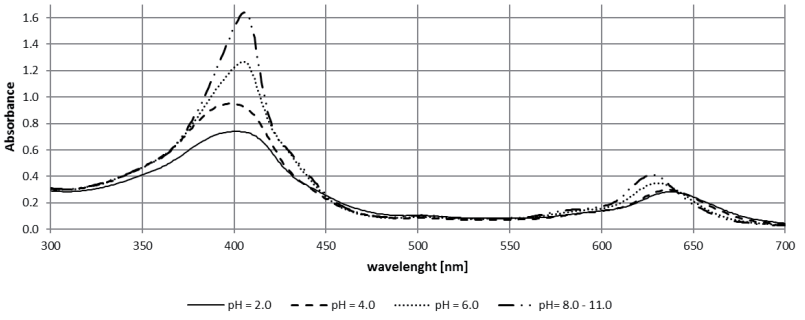

Fig. 7. Absorption spectrum of E141(ii) at different $\mathrm{pH}$ levels, concentration $0.0257 \mathrm{~g} \cdot \mathrm{dm}^{-3}$.

taken on using the above-mentioned $\mathrm{pH}$ values of the solutions. As examples, the spectra are shown in Fig. 6 for E141(ii) concentration $0.0257 \mathrm{~g} \cdot \mathrm{dm}^{-3}$. It is easily seen from Fig. 7 that at high $\mathrm{pH}$ levels of 8,10 , and 10.9, the spectra are nearly identical. However, starting at $\mathrm{pH} 6$ the maximum of the spectra drastically diminishes. The reasons for this phenomenon can be related to the loss of an atom of copper from the center of the porphyrin ring of chlorophyllins due to the impact of added hydrochloric acid [38]. Analysis of the absorption spectrum proves that, except for the above-described phenomenon, lowering $\mathrm{pH}$ with hydrochloric acid does not cause other changes in the structure of the examined dye.

Fig. 8 shows the percentage of E141(ii) loss during the photocatalytic process in the presence of titanium dioxide after 35-minute irradiation (initial substrate concentrations: $5.50 \cdot 10^{-3}, 1.53 \cdot 10^{-2}$, and $2.57 \cdot 10^{-2} \mathrm{~g} \cdot \mathrm{dm}^{-3}$ ), depending on the initial $\mathrm{pH}$ of the reaction medium.

As presented in this figure, the process of photocatalytic decolourization of the dye is independent of environmental $\mathrm{pH}$, but the loss of the substrate is dependent on the initial $\mathrm{pH}$ of the environment. The increase of $\mathrm{pH}$ during reaction causes inhibition of a photodegradation of E141(ii). Photodecolourization reaches minimum value at a $\mathrm{pH}$ of 8 . However, special attention deserves the fact that the decrease of the initial $\mathrm{pH}$ of the medium increases the efficiency of photocatalytic decolourization, which reached $100 \%$ at $\mathrm{pH}$ of 2 , regardless of the initial solution concentration. Discussing the results obtained in the present study cannot ignore the possible role of copper

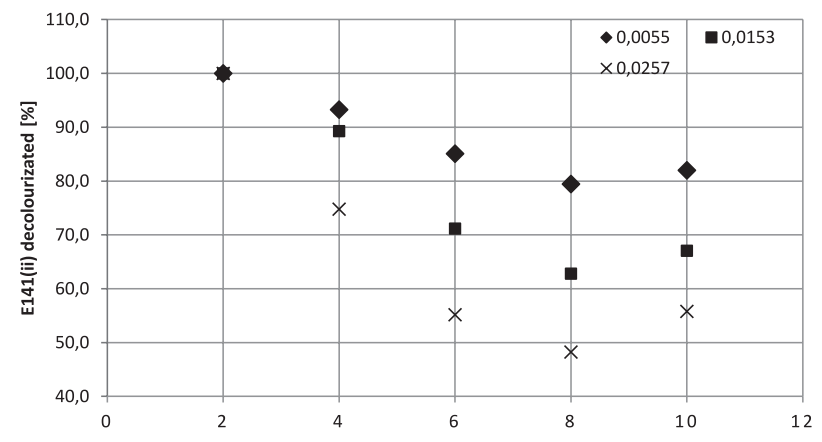

Fig. 8. The dependence of the percentage amount of E141(ii) photodecolourizated in the presence of $\mathrm{TiO}_{2}$ after 35-minute illumination vs. $\mathrm{pH}$. 
ions, which are an integral component of chlorophyllins. Cai, Kubota, and Fujishima reported [39] that the presence of $\mathrm{Cu}$ (II) in a solution leads to the formation of $\mathrm{H}_{2} \mathrm{O}_{2}$, although the mechanism of this phenomenon is not well explored. The authors suggest that this process takes place as follows:

$$
\begin{gathered}
\mathbf{O}_{2}^{-}+\mathrm{Cu}(\mathrm{II}) \rightarrow \mathrm{O}_{2}+\mathrm{Cu}(\mathrm{I}) \\
\mathbf{O}_{2}^{-}+2 \mathrm{H}^{+}+\mathrm{Cu}(\mathrm{I}) \rightarrow \mathrm{H}_{2} \mathbf{O}_{2}+\mathrm{Cu}(\mathrm{II})
\end{gathered}
$$

It does not exclude the occurrence of the reduction process of $\mathrm{Cu}(\mathrm{II})$ ions on the surface of the irradiated $\mathrm{TiO}_{2}$ involving photochemically generated electrons. The generated $\mathrm{H}_{2} \mathrm{O}_{2}$ can be formed into highly reactive hydroxyl radicals under UV irradiation, radical $\mathrm{O}_{2}{ }^{\circ}$, $\mathrm{e}^{-}$ from the conduction band of $\mathrm{TiO}_{2}$, also during the Fenton reaction [39-40]:

$$
\mathrm{Cu}^{+}+\mathrm{H}_{2} \mathrm{O}_{2} \rightarrow \mathrm{Cu}^{2+}+\mathrm{HO}^{-}+\mathrm{HO}^{-}
$$

It can be assumed that some $\mathrm{Cu}$ (II) ions "released" from chlorophyllins during its photodegradation are photodeposited onto the surface of $\mathrm{TiO}_{2}$. In this case $\mathrm{Cu}$ (II) ions became a "trap" for photogenarated electrons, simultaneously reduced to $\mathrm{Cu}(0)$ or $\mathrm{Cu}(\mathrm{I})$. This process results in the rapid oxidation of photodegradated substrates [40, 42-44]. The efficiency of photocatalytic degradation of organic compounds in the presence of $\mathrm{Cu}$ (II) depends on many factors: the amount and form of the occurrence of copper ions in solution (oxides, complex compounds), and the method of the photocatalyst input or $\mathrm{pH}$ of the solution $[39-40,43,45]$.

\section{Conclusions}

As a result of studies on the use of photocatalytic and photolytic processes of the commercial form of the dye E141(ii) carried out in model systems, it has been confirmed that copper complexes of chlorophyllins present in the dye are photodecolourizated in an aqueous medium due to the photocatalysis reaction using titanium dioxide as a catalyst as well as direct photolysis processes (without $\mathrm{TiO}_{2}$ ). The presence of titanium dioxide in the photodecolourization process leads to an approximately three-fold increase of process efficiency. The efficiency of decolourization in the concentration range $5.20 \cdot 10^{-3}-2.60 \cdot 10^{-2} \mathrm{~g} \cdot \mathrm{dm}^{-3}$ is directly proportional to the initial concentration of the solution. Kinetic study of the photocatalytic decolourization of the dye over a range of concentrations confirms that this process occurs according to the Langmuir-Hinshelwood model. The decrease of $\mathrm{pH}$ during the process of photodecolourization of E141(ii) proves that acidic derivatives are formed. The $\mathrm{pH}$ of the reaction significantly affects the efficiency of photocatalytic decolourization of copper complexes of chlorophyllins, with the $\mathrm{pH}$ increase ranging from 2 to 8 , causing the inhibition of decolourization of the dye.

\section{Acknowledgements}

We would like to thank Professor Andrzej Sobczyński for all valuable comments and suggestions given during the investigation and preparation of this publication.

\section{References}

1. OLLER I., MALATO S., SANCHEZ-PEREZ J.A. Combination of Advanced Oxidation Processes and biological treatments for wastewater decontamination - A review. The Science of the Total Environment, 409, 4141, 2011.

2. EVENIDOU E., BIZANI E., CHRISTOPHORIDIS C., FYTIANOS K. Heterogeneous Photocatalytic Photodegradation of Prometryn in Aqueous Solutions under UV-VIS Irradiation. Chemosphere, 68, 1877, 2007.

3. QUASIM W., MANE A.V., Characterization and treatment of selected food industrial effluents by coagulation and adsorption techniques. Water Resources and Industry, 4, 1, 2014.

4. SOBCZYŃSKI A., GIMENEZ J., CERVERA-MARCH S. A Fluidized Photoreactor Design for Water Detixification by Photocatalysis. Polish Journal of Applied Chemistry, 40, 103, 1996.

5. MALATO S., FERNANDEZ-IBANEZ P., MALDONADO M.I., BLANCO J., GERNJAK W. Decontamination and Disinfection of Water by Solar Photocatalysis: Recent Overview and Trends. Catalysis Today, 147, 1, 2009.

6. ROSENFELDT E., LINDEN K., CANONICA S., GUNTER $\mathrm{U}$. Comparison of the Efficiency of $\bullet \mathrm{OH}$ Radical Formation During Ozonation and the Advanced Oxidation Processes $\mathrm{O}_{3} / \mathrm{H}_{2} \mathrm{O}_{2}$ and $\mathrm{UV} / \mathrm{H}_{2} \mathrm{O}_{2}$. Water Resources, 40, 3695, 2006.

7. WERT E., ROSARIO-ORTIZ F., SNYDER S. Effect of Ozone Exposure on the Oxidation of Trace Organic Contaminats in Wastewater. Water Resources, 43, 1005, 2009.

8. CHONG M.N., JIN B., CHOW C.W.K., SAINT C. Recent Developments in Photocatalytic Water Treatment Technology: A Review. Water Resources, 44, 2997, 2010.

9. CHENG M., ZENG G., HUANG D., LAI C., XU P., ZHANG C., LIU Y. Hydroxyl radicals based advanced oxidation processes (AOPs) for remediation of soils contaminated with organic compounds: A review. Journal of Chemical Engineering, 284, 582, 2016.

10. SOBCZYŃSKI A., GIMENEZ J., CERVERA-MARCH S. Photodecomposition of Phenol in a Flow Reactor: Adsorption and Kinetics, Monatschefte für Chemie, 128, 1109, 1997.

11. SOBCZYŃSKI A., DOBOSZ A. Water Purification by Photocatalysis on Semiconductors Polish Journal of Environmental Studies, 10, 195, 2001.

12. ROBERT D., MALATO S. Solar Photocatalysis: A Clean Process for Water Detoxification, The Science of the Total Environment, 291, 85, 2002.

13. NAEEM K., FENG O. Parameters Effect on Heterogeneous Photocatalysed Photodegradation of Phenol in Aqueous Dispersion of $\mathrm{TiO}_{2}$, Journal of Environmental Science, 21, 527, 2009.

14. CHANG C.Y., HSIEH Y.H., HSIEH L.L., YAO K.S., CHENG TC. Establishment of Activity Indicator of $\mathrm{TiO}_{2}$ Photocatalytic Reaction - Hydroxyl Radical Trapping Method, Journal of Hazardious Materials, 166, 897, 2009. 
15. IBHANDON A.O., FITZPATRICK P. Heterogeneous Photocatalysis: Recent Advanced Applications. Catalysts, 3, 189, 2013.

16. ANTONOPOULOU M., EVGENIDOU E., LAMBROPOULOU D., KONSTANTIONOU I. A review of advanced oxidation processes for the removal of taste and odor compounds from aqueous media. Water Resources, 53, 15, 2014.

17. CHEN D., RAY A.K. Removal of toxic metal ions from wastewater by semiconductor photocatalysis. Chemical Engineering Science, 56, 1561, 2001.

18. WAHYUNI E.T, APRILITA R., HATIMAH H., WULANDARI A.M., MUNDASIR M. Removal of toxic metal ions in water by photocatalytic method. American Chemical Science Journal, 5 (2), 194, 2015.

19. BAVCON KRAJL M., TREBSE P., FRANCO M. Applications of bioanalytical techniques in evaluating advanced oxidation processes in pesticide photodegradation. Trends in Analytical Chemistry, 26 (11), 1020, 2007.

20. VALLEJO M., FRASNEDO SAN ROMAN M., ORTIZ I., IRABIEN A. Overview of the PCDD/Fs photodegradation potencial risk in the application of advanced oxidation processes (AOPs) to wastewater treatment. Chemosphere, 118, 44, 2015.

21. LUTTERBECK C.A., BAGINSKA E., MACHADO E.L., KUMMERER K. Removal of the anti-cancer drug methotrexate from water by advanced oxidation processes: Aerobic bioderadation and toxity studies after treatment. Chemosphere, 141, 290, 2015.

22. RAJCA M., BODZEK M., CICHY J. Kinetyka degradacji kwasów fulwowych w zintegrowanym procesie fotoutlenianie-ultrafiltracja. Ochrona Środowiska, 33 (3), 63, 2011 [In Polish].

23. ZMUDZIŃSKI W. Preliminary Results of Purification of Dairy Sewage by Photocatalysis on Titania. Polish Journal Environmental Studies, 18,1225, 2009.

24. ZMUDZIŃSKI W. Preliminary Results of Glucose Oxidation by Photocatalysis on Titanium Dioxide- primary intermediates. Physicochemical Problems of Mineral Processing, 45, 141, 2010.

25. DASHWOOD R.H. The importance of using pure chemicals in anti/mutagenicity studies: chlorophyllin as a case in point. Mutation Research, 381, 283, 1997.

26. TUMOLO T., LANFER-MARQUEZ U.M. Copper chlorophyllin: a food colorant with bioactive properties? Food Research International, 46, 451, 2012.

27. SOUTSAS K., KARAYANNIS V., POULIOS I., RIGA A., NTAMPEGLIOTIS K., SPILIOTIS X., PAPAPOLYMEROU G. Decolorization and photodegradation of reactive azo dyes via heterogenous photocatalytic processes, Desalination, 250, 345, 2010.

28. ZANGENEH H., ZINATIZADEH A.A.L., HABIBI M., AKIA M., HASNAIN ISA M., Photocatalytic oxidation of organic dyes and pollutants in wastewater using different modified titanium dioxides: A comparative review, Journal of Industrial and Engineering Chemistry, 26, 1, 2015.

29. KATHIRAVAN A., RENANATHAN R., Effect of anchoring group on the photosensitization of colloidal $\mathrm{TiO}_{2}$ nanoparticles with porphyrins, Journal of Colloid and Interface Science, 331, 401, 2009.
30. ZMUDZIŃSKI W. Preliminary Results of Purification of Dairy Sewage by Photocatalysis on Titania. Polish Journal Environmental Studies, 18, 1225, 2009.

31. ZMUDZIŃSKI W. Preliminary results of glucose oxidation by photocatalysis on titanium dioxide- primary intermediates. Physicochemical Problems of Mineral Processing, 45, 141, 2010.

32. OKAMOTO K., YAMMAMOTO Y., TANAKA H., ITAJA A. Kinetics of Heterogeneous Photocatalytic Decomposition over Anatase $\mathrm{TiO}_{2}$ Powder. Bulettin of the Chemical Society of Japan, 58, 2023, 1985.

33. TURKS C.S., OLLIS D.F. Photocatalytic Degradation of Organic Water Contaminants: Mechanisms Involving Hydroxyl Radical Attack. Journal of Catalysis, 122, 178, 1990.

34. ZMUDZIŃSKI W., SOBCZYŃSKA A., SOBCZYŃSKI A. Oxidation of Phenol and Hexanol on their Binary Mixtures on Illuminated Titania: Kinetic Studies. Reaction Kinetics and Catalysis Letters, 90, 293, 2007.

35. ZMUDZIŃSKI W. Removal of o-Cresol from Water by Adsorption/Photocatalysis, Polish Journal of Environmental Studies, 19, 1353, 2010.

36. FARAG A.A.M., Optical absorption of sodium copper chlorophyllin thin films in UV-Vis-NIR region, Spectrochimica Acta Part A, 65, 667, 2006.

37. BARD A.J. Photoelectrochemistry and Heterogeneous Photocatalysis at Semiconductors. Journal of Photochemistry, 10, 59, 1979.

38. HUMPREY A.D. Chlorophyll as a Color and Functional Ingredient. Journal of Food Science, 69, C422, 2004.

39. CAI R., KUBOTA Y., FUJISHIMA A. Effect of copper ions on the formation of hydrogen peroxide from photocatalytic titanium dioxide particles. Journal of Catalysis, 219, 214, 2003.

40. LITTER M.I., Heterogeneous photocatalysis. Transition metal ions in photocatalytic systems. Applied Catalysis B: Environmental, 23, 89, 1999.

41. CIESLA P., KOCOT P., MYTYCH P., STASICKA Z. Homogeneous photocatalysis by transition metal complexes in the environment. Journal of Molecular Catalysis A: Chemical, 224, 17, 2004.

42. RAUF M.A., MEETANI M.A., HISAINDEE S. An overview on the photocatalytic degradation of azo dyes in the presence of $\mathrm{TiO}_{2}$ doped with selective transition metals. Desalination, 276 (1), 13, 2011.

43. AL-MUHTASEB A.H., KHRAISHEHB M. Photocatalytic removal of phenol from refinery wastewater: Catalytic activity of $\mathrm{Cu}$-doped titanium dioxide. Journal of Water Process Engineering, 8, 82, 2015.

44. ANDARDE M.A., Carmona R., MESTRE A.S., MATOS J., CARVALHO A.P., ANIA C.O. Visible light driven photooxidation of phenol on $\mathrm{TiO}_{2} / \mathrm{Cu}$-loaded carbon catalysts. Carbon, 76, 183, 2014.

45. ZUAS O., BUDIMAN H. Synthesis of Nanostructured Copper-doped Titania and Its Properties, Nano-Micro Letters, 5 (1), 26, 2013. 